\title{
Perspectivas do planejamento sob o ponto de vista dos profissionais da Estratégia Saúde da Família.
}

\section{Perspectives of planning from the point of view of professional Family Health Strategy.}

\section{Planificación de perspectivas desde el punto de vista de los profesionales de la Estrategia de Salud de la Familia.}

Polyana da Costa RIBEIRO ${ }^{1}$

José Ivo dos Santos PEDROSA ${ }^{2}$

Lídya Tolstenko NOGUEIRA ${ }^{3}$

Maria Fátima de SOUSA ${ }^{4}$

RESUMO: O artigo analisa similaridades e divergências do diagnóstico comunitário no âmbito do Planejamento local das equipes saúde da família em Teresina. Fundamentou-se em estudo de caso e grupo focal com equipes pertencentes a uma mesma base territorial, envolvendo hospital, centro de saúde da zona urbana e rural. Discutem-se três dimensões analíticas: Processo de planejamento, diagnóstico no planejamento das equipes de saúde e facilidades/limites. Evidenciou-se que o planejamento é incipiente, imediatista, individualizado e insatisfatório às necessidades da demanda. As intervenções dos atores sociais não implicaram ações sustentáveis, reflexo da verticalidade dos programas e de distorções no processo de implantação das equipes. Urge dos gestores vigilância para com o alicerce organizacional da atenção básica, que é o diagnóstico, além de implementar estratégias para a saúde do homem, do adolescente, acamados e cuidadores e educação coletiva, eixos negligenciados.

Descritores: Atenção Básica. Saúde da Família. Diagnóstico da Situação em Saúde. Planejamento.

\footnotetext{
ABSTRACT: The article looks at similarities and differences of the community diagnosis within the local planning of family health teams in Teresina. Was based on case study and focus group with teams belonging to the same territorial basis, involving hospital, health center of urban and

1 Mestre em Ciências e Saúde pela Universidade Federal do Piauí (UFPI). Enfermeira da Estratégia Saúde da Família de Teresina.

2 Doutor em Saúde Coletiva pela Universidade Estadual de Campinas (UNICAMP).

3 Doutora em Enfermagem pela Universidade Federal do Rio de Janeiro (UFRJ).

4 Doutora em Ciências da Saúde pela Universidade de Brasília (UnB). Universidade de Brasília, Núcleo de Estudos em Saúde Pública (NESP/UnB). Programa de Pós Graduação em Saúde Coletiva.
}

// Tempus, actas de saúde colet, Brasília, 8(4), 269-285, dez, 2014. 
rural area. Discusses three analytical dimensions: planning process, diagnosis in the planning of health teams and facilities/limits. It was evidenced that the planning is in its incipient, short-term, individualized and unsatisfactory demand needs. The interventions of the social actors have not involved sustainable actions, reflecting the verticality of the programmes and of distortions in the deployment process of the teams. Urge vigilance to managers with the organizational foundation of primary care, which is the diagnosis, in addition to implementing strategies for men's health, adolescent, bedridden and caregivers and collective education, neglected.

Descriptors: Primary Care. Family Health. Diagnosis of Health Situation. Planning.

RESUMEN: El artículo analiza las similitudes y diferencias de la diagnosis de la comunidad en la planificación local de los equipos de salud familiar en Teresina. Se basó en el estudio de caso y encuentros con equipos pertenecientes a la misma base territorial, con el hospital, centro de salud del área urbano y rural. Analiza tres dimensiones analíticas: proceso, diagnóstico en la planificación de los equipos de salud y servicios/límites de planificación. Se evidenció que la planificación está en su incipiente, a corto plazo, las necesidades de la demanda individualizada e insatisfactorias. Las intervenciones de los actores sociales no han involucrado acciones sostenibles, lo que refleja la verticalidad de los programas y de las distorsiones en el proceso de implementación de los equipos. Instar a la vigilancia a los administradores de la Fundación de la organización de la atención primaria, que es el diagnóstico, además de implementar estrategias para la salud de los hombres, adolescente, postrado en cama y los cuidadores y educación colectiva, descuidado.

Descriptores: Atención primaria de salud. Salud de la familia. Diagnóstico de la situación en salud. Planificación.

\section{INTRODUÇÃO}

Quando a cobertura populacional dos programas governamentais brasileiros for igual ou superior a 70\%, maiores serão os níveis de consolidação das táticas, o que possibilita mudar do modelo convencional (hospitalocêntrico) para o atualmente proposto (vigilância em saúde) ${ }^{(1)}$. A expansibilidade da estratégia Saúde da Família (eSF) por si só, não garante a (re) organização efetiva da atenção básica. Terá potencialidade para tal intento se a universalidade do acesso ocorrer de forma adjacente ao diagnóstico comunitário de saúde, que deve ser a pedra angular para o planejamento e gestão dos sistemas de saúde ${ }^{(2)}$.

A eSF possui peculiaridades: modifica práticas tradicionais de assistência por um novo processo de trabalho; obedece aos princípios da integralidade, resolutividade, hierarquização e holismo; trabalha com tecnologias de baixo custo e de alta complexidade na compreensão do processo saúde-doença-cuidado, e, funciona com territorialização, adstrição de clientela, responsabilizandose pelo mapeamento, cadastramento, acompanhamento da população, diagnóstico e planejamento, observando critérios de risco, vulnerabilidade, resiliência e o imperativo ético de que as 
necessidades de saúde sejam acolhidas em suas singularidades ${ }^{(3)}$. Essas prerrogativas exigem equipe multidisciplinar composta por 01 médico, 01 enfermeiro, 01 auxiliar de enfermagem, 01 dentista, 01 técnico de higiene dental. O número de Agentes Comunitários de Saúde (ACS) deve ser suficiente para cobrir $100 \%$ da microárea, com o máximo de 750 pessoas por ACS e de até 12 ACS por equipe, a qual deve responsabilizar-se por, no máximo, 4.000 pessoas, respeitando-se a equidade $^{(3)}$.

Espera-se que a Equipe Saúde da Família (ESF) organize as atividades com base em planejamento para que dê soluções às necessidades comunitárias, com abordagem inovadora, acessível, diversificada, inclusiva, não hierárquica e ético-democrática ${ }^{(4)}$. Isso implica romper os muros dos serviços de saúde e dirigir um olhar sistêmico para a população direcionando ações para as demandas programática (que usufruem os pacotes assistenciais), espontânea (com suas queixas e intercorrências) e reprimida (que se quer busca atendimentos nas Unidades de Saúde).

A integralidade perpassa na inserção do diagnóstico comunitário como tecnologia aos processos de trabalho. A Organização Pan-Americana de Saúde ${ }^{(5)}$ recomenda oito eixos para o planejamento: 1) Zona estratégica - delimitação da área com instituições permanentes e que desenvolvam intervenções; 2) Diagnóstico comunitário - levantamento de problemas baseados em evidências; 3) Radiografia da coordenação operacional - identificação de instituições públicas, privadas e nãogovernamentais facilita o trabalho e evita duplicidade de tarefas; 4) Mapa de serviços - descrição cartográfica das organizações explicitando os programas, as ações e atividades na zona estratégica; 5) Suportes para referenciar pacientes; 6) Objetivos claros evita a estagnação do trabalho, as limitações técnico-metodológicas e permite reflexão crítica; 7) Comunidade estratégica envolve microprocessos com a intencionalidade de diminuir a verticalidade dos programas; capacitar instituições a partir da prática; formar grupos para o fortalecimento comunitário; trabalhar com alternativas que permitam às organizações perceberem diferentes formas de trabalho e discutir junto à população o planejamento e 8) Desenvolvimento de abordagens sustentadas, o que desperta compartilhamento das responsabilidades com a população .

Seguindo essas proposições, a Organização Mundial de Saúde ${ }^{(6)}$ adverte sobre a necessidade de reformas na cobertura universal, na prestação dos serviços de saúde, nas políticas de saúde e nas lideranças, sendo a capilaridade guiada por negociações, participação e inclusão social, no sentido de romper com gestões autoritárias bem como o laissez-faire descompromissado do Estado, o que implicará na amplificação e personalização da agenda de saúde aos contextos singulares.

Tais conjecturas são defendidas por instituições nacionais, como o Conselho Nacional de Secretários de Saúde ${ }^{(7)}$ e distritais, a exemplo dos Conselhos Locais de Saúde ${ }^{(8)}$, que é o órgão colegiado máximo do Sistema Único de Saúde (SUS) na área de abrangência das unidades, com funções deliberativas, normativas e fiscalizadoras, devendo realizar ações tais como: diagnosticar a realidade de saúde do bairro; planejar ações a partir de problemas; acompanhar a execução do plano de trabalho das equipes, deliberar mecanismos para corrigir distorções; avaliar a qualidade 
do atendimento oferecido à comunidade; possibilitar à população amplo conhecimento do SUS além de desenvolver e participar de projetos intersetoriais.

Sabendo-se que o diagnóstico comunitário deve constituir a força motriz para planejar as ações, e tendo em vista a lacuna na atuação dos conselhos, é pertinente buscar respostas para a questãoproblema: O diagnóstico comunitário no âmbito do planejamento local orienta a prática das equipes saúde da família nos territórios adstritos? É salutar esse questionamento dada a rápida expansão da eSF em Teresina, com cobertura de 96\%, e pela efetivação das políticas públicas em um contexto no qual já perpassaram 34 anos de Alma-Ata, 23 anos do SUS, 21 anos de PACS e 18 anos da eSF, o que subsidiará a gestão a avaliar as concepções do diagnóstico comunitário e a conduta adotada no planejamento, no que tange ao pensamento estratégico ou manutenção da normatividade ministerial. Nessa perspectiva, este artigo teve como objetivo geral analisar similaridades e divergências do diagnóstico comunitário no âmbito do planejamento sob o ponto de vista dos profissionais das equipes saúde da família em Teresina (PI).

\section{METODOLOGIA}

Tratou-se de uma pesquisa qualitativa baseada em estudo de caso e grupo focal, pela eficácia na identificação de consensos e diferenças além de possibilitar a emersão de polêmicas da rotina de trabalho(9).

O estudo realizou-se em Teresina (PI), que apresenta 234 ESF, sendo 213 localizadas na zona urbana e 21 na zona rural. Selecionou-se intencionalmente a Regional de Saúde Centro-Norte e como território de jurisdição, a grande Região da Santa Maria da Codipi, por reunir distintos cenários de funcionalidade da eSF no município, abrangendo centro de saúde e hospital. Para tal, adotou-se o conceito de território defendido por Moken e Barcellos ${ }^{(10)}$, como sendo o lugar que apresenta, além de uma extensão geométrica, um perfil demográfico, epidemiológico, administrativo, tecnológico, político, social e cultural que o caracteriza como território em permanente construção.

A amostra constituiu-se de três equipes inseridas em centros de saúde (zona urbana e rural) e em ambiente hospitalar. Procurou-se eleger as equipes com mais de um ano de implantação, além dos profissionais com formação específica em Saúde Pública, Saúde da Família ou similares.

Realizaram-se três grupos focais, sendo que cada equipe participou de uma sessão. O tempo médio de duração foi de 1 hora 14 minutos e 52 segundos, realizado nas unidades de saúde. Participaram 26 sujeitos: 03 médicos, 03 enfermeiras, 01 dentista, 03 técnicas em enfermagem, 02 técnicas em higiene dental e 14 ACS.

Os encontros foram conduzidos pela moderadora (pesquisadora), com o apoio do observadorexterno. No debate, utilizou-se a técnica de moderação não diretiva ou o estilo semi-estruturado, conforme espontaneidade dos grupos. Organizou-se o guia em eixos temáticos: I) processo do planejamento, II) efetividade do planejamento, III) habilidade e experiência profissional e IV) 
perspectivas em relação ao planejamento. Para cada bloco, delineou-se a questão orientadora da discussão. As perguntas foram: I) Como acontece o processo de planejamento?, II) O planejamento é coerente com os problemas que a população apresenta?, III) Relatem a experiência profissional em relação ao planejamento local, e IV) Como deve ser o planejamento? E qual o objetivo de planejar? O observador-externo fez o monitoramento do gravador de voz, do tempo, além das reações dos grupos focais.

Os dados foram coletados em maio/junho de 2011, após a validação do instrumento. As falas foram submetidas à leitura flutuante, com a finalidade de buscar a essência/significância. Empregouse a análise temática ${ }^{(11)} \mathrm{e}$ identificaram-se três dimensões: 1) Processo de planejamento (no qual discutiu-se conceito, grau de participação dos técnicos e da comunidade e temas das reuniões); 2) Diagnóstico no planejamento das equipes de saúde (elencou-se as significações do diagnóstico a partir de critérios como: (in)formalização, complexidade das etapas, importância, objetivos, lacunas e perspectivas; 3) Facilidades (apontaram-se elementos inerentes ao profissional, ao cotidiano da equipe, à população e à intersetorialidade) e Limites (mencionaram-se o perfil territorial, questões organizativas dos serviços que dialogam com a eSF e processo de trabalho).

Os sujeitos assinaram Termo de Consentimento Livre e Esclarecido, conforme a Resolução 196/96, sendo assegurado sigilo. Os grupos foram identificados por letras (A- Hospital, B- Centro de Saúde urbano e C- Centro de Saúde rural). O projeto foi aprovado pelo Comitê de Ética da Universidade Federal do Piauí (UFPI) conforme Certificado de Apresentação para Apreciação Ética (CAAE): 0.463.0.045.000-10.

\section{RESULTADOS E DISCUSSÃO}

As ESF do estudo são antigas quanto ao tempo de implantação, o que denota familiaridade com o Programa. Apresentam como modelo organizacional o Programa Saúde da Família (PSF) com o Programa de Saúde Bucal (PSB), embora duas equipes tenham iniciado como Programa dos Agentes Comunitários de Saúde (PACS).

No grupo A, constatou-se a inexistência de direção colegiada, o que influencia negativamente o diagnóstico comunitário, planejamento e tomada de decisões. Diferentemente, os grupos B e $\mathrm{C}$, têm direção colegiada, da qual participam médicos, enfermeiros e dentistas, com rodízio a cada seis meses. Inicia a gestão o profissional que está há mais tempo na equipe, o que confere maior organicidade ao processo de trabalho. Entretanto, servidores admitidos de longa data podem tornar-se resistentes a mudanças, perpetuando práticas tradicionais. Outra convergência foi a inexpressividade dos Conselhos Locais de Saúde, o que revela invisibilidade da participação social na saúde.

Quanto à territorialização do bairro (áreas/microáreas) e sua distribuição geográfica em mapas, foi unânime que é imprescindível, porém, ao serem questionados sobre a disponibilização do 
documento, o Grupo B relatou sua inexistência na forma de mapas, embora as ações fossem territorializadas, enquanto os Grupos A e C apresentaram-no respectivamente, no mural do consultório da enfermeira (restringindo-se a informação aos técnicos) e no mural da Unidade de Saúde (compartilhando-se as noções cartográficas aos usuários).

Amaioria das famílias transita entre a indigência e a pobreza, entretanto apresentam singularidades em relação à situação de ocupação (invasão, conjunto habitacional oficial ou povoados), o que, juntamente com sua localização em área urbana, rural ou em transição, são critérios importantes na determinação do quantitativo de famílias acompanhadas pelas equipes, sendo menor no grupo $\mathrm{C}$, pela baixa densidade demográfica e maiores dificuldades de infraestrutura, quando comparado à zona urbana. No tocante ao universo de usuários acompanhados, percebeu-se que as equipes do estudo seguem o padrão ministerial, que é assistir até 3.450 pessoas $^{(12)}$.

Trabalhar em contextos vulneráveis exige modelo assistencial integral. Nesse sentido, a vigilância à saúde configura o protótipo que melhor articula operações para o enfrentamento de situações de saúde, já que identificam riscos, danos e sequelas que incidem sobre indivíduos, famílias, ambientes coletivos e grupos sociais de modo a possibilitar intervenções que promovam e preservem a saúde, como o estabelecimento do planejamento e programação local ${ }^{(13)}$.

Reiterando essa discussão, percebe-se que é surreal atribuir à eSF a responsabilidade de redutor das vulnerabilidades, iniquidades e desigualdades, haja vista que muitas das questões sociais extrapolam o domínio da saúde, por ser a eSF auto-limitada em si mesmo, o que exige parcerias de outros setores da sociedade civil organizada ${ }^{(14)}$.

\section{Processo de planejamento local}

O planejamento é uma atividade que propicia monitorar a situação, o que facilita o trabalho, direcionando para prioridades. Entretanto, prevaleceu uma definição mais individualizada do que coletiva sobre o seu significado. Os atores voltam-se para o curto prazo, trabalhando sob a perspectiva de programação (cronogramas), discutidos nas reuniões semanais, onde o foco de atenção é a demanda programática. A participação dos atores sociais nas reuniões de planejamento foram qualificadas como esporádica, espontânea, à convite ou obrigatória, conforme o quadro 1 .

QUADRO 1 - Representação dos profissionais nas reuniões de planejamento das equipes da Santa Maria da Codipi. Teresina (PI), 2011.

\begin{tabular}{|c|c|c|c|}
\hline PROFISSIONAIS & $\begin{array}{c}\text { GRUPO A } \\
\text { Hospital }\end{array}$ & $\begin{array}{c}\text { GRUPO B } \\
\text { Centro de Saúde } \\
\text { urbano }\end{array}$ & $\begin{array}{c}\text { GRUPO C } \\
\text { Centro de Saúde } \\
\text { rural }\end{array}$ \\
\hline Médico & Esporádica & Espontânea & Espontânea \\
\hline Enfermeiro & Espontânea & Espontânea & Espontânea \\
\hline Técnico de Enfermagem & Espontânea & Espontânea & Espontânea \\
\hline Dentista & A convite & A convite & A convite \\
\hline Técnico de Higiene Dental & A convite & A convite & A convite \\
\hline
\end{tabular}




\begin{tabular}{|c|l|l|l|l|}
\hline $\begin{array}{c}\text { Agentes Comunitários de } \\
\text { Saúde }(\mathrm{ACS})\end{array}$ & Obrigatória & Espontânea & Espontânea & Espontânea \\
\hline
\end{tabular}

Fonte: RIBEIRO, P.C. Diagnóstico comunitário no planejamento estratégico situacional das equipes saúde da família em Teresina: estudo de caso. Dissertação (Mestrado em Ciências da Saúde) - UFPI. Teresina: 2012.

A diversidade de participações deve-se ao perfil profissional do enfermeiro, que, desde a graduação, é sensibilizado para atividades gerencial-administrativas, assumindo a coordenação e portando-se como articulador entre os integrantes da equipe, sobretudo, entre aqueles profissionais de quem exerce supervisão: o técnico de enfermagem e os ACS. Por desempenhar tais ações com habilidade, lhe é atribuído o papel de chefia e de primeiro relator nas reuniões, o que parece estar fortemente incorporado ao seu processo de trabalho. O médico e o dentista, diferentemente, apresentam uma formação mais voltada para a clínica e distanciam-se da gerência, definindo o envolvimento participativo nas reuniões de forma casual (esporádica) ou mediante solicitação de comparecimento (a convite).

A liderança de enfermeiros e médicos nas reuniões de planejamento decorre do pioneirismo dessas profissões quando da implantação da eSF. Além disso, as capacitações institucionais são mais direcionadas aos médicos e enfermeiros, sendo atribuído a esses profissionais a responsabilidade de repassar a pauta das discussões aos demais membros da equipe, os quais participam dos treinamentos de forma esporádica.

A obrigatoriedade referida por alguns ACS revela uma gestão autocrática para o grupo A, que utiliza mecanismos organizacionais como livro de reunião com a pauta e assinatura, funcionando como folha de ponto, conforme a fala: "A gente tá aqui toda sexta, se não vem, tem que avisar porque é dado falta". Para o grupo B, a participação ocorre de forma voluntária. E no grupo $\mathrm{C}$, a cooperação também é livre, simulando mais compromisso dos profissionais do que norma organizacional.

A participação popular é indireta, passiva e mediada pelos ACS, por ser o elo entre a população e o centro de saúde: “... a população participa junto com os Agentes de Saúde. Como eles visitam as famílias..., vão trazendo as reclamações, os anseios e, isso é exposto aqui... aos poucos vai sendo debatido. Agora... a atuação de lideranças comunitárias, isso não tem... essa participação vem indiretamente dos próprios ACS, que sentam... e expõem principalmente à enfermeira..." (Grupo $B)$. Nos grupos A e C notou-se uma vivência participativa ativa e utilitarista, sendo a promoção de atividades determinadas por negociações recíprocas, pois no dizer dos participantes: "não se dá o peixe, ensina-se a pescar: o pelotão mirim nos ajudou nos mutirões da dengue, em arraiás para arrecadar dinheiro para o curso das gestantes e em troca implantamos a carteira do adolescente, imunização e palestras..." (Grupo A). "Tem os agentes de endemias no caso da dengue...; apoio de pessoas da própria comunidade para fazer o destino correto do lixo, além da associação de moradores" (Grupo C). 
O conteúdo discutido nas reuniões compreende temas administrativos (cronograma, produtividade, falta de materiais e insumos), normativos (regras de funcionamento das unidades, informes do Ministério/Regional de Saúde e seguimento dos grupos de risco) e intercorrências do serviço e comunidade (momento de escuta dos problemas apontados pelos ACS, além de reclamações da população em relação aos profissionais das ESF).

São escassos os momentos de reunião das equipes para planejar as ações, sendo que, no seu cotidiano as equipes ficam restritas quase que exclusivamente às ações programáticas. Não se observam articulação das ações nem interação dos agentes. Os trabalhos especializados são realizados de forma parcelar, fragmentados, justapostos com duplicação de ações e sem fluxograma de atividades, o que impõe limites para a realização do planejamento assistencial interdisciplinar ${ }^{(15)}$, o que ratifica os achados deste estudo. A comunicação aberta, típica das unidades de pequeno porte, facilita a adesão aos planos, mas não garante necessariamente a participação efetiva dos atores, já que se adere a uma causa sem compartilhar os princípios de modo genuíno ${ }^{(16)}$. Ao implementar uma proposta é importante a discussão com todos os profissionais sobre as finalidades almejadas, além da busca do consenso. Quando isso não é considerado, o plano torna-se surreal para o grupo, configurando-se como conjunto de boas intenções que não levam a resultados $\operatorname{concretos}^{(17)}$.

Percebe-se que a riqueza do planejamento está em questionar e procurar responder às perguntas que inquietam: o que, por que, como, quando, com quem, com o quê. Essas indagações devem estar explicitadas no plano de ação, que documenta acordos estabelecidos, indicando as coordenadas do sistema para que as metas sejam alcançadas. Isso exige flexibilidade por parte da instituição, administradores e atores, já que é mais adequado ao processo de trabalho a incorporação de diversos instrumentos, como tem demonstrado Tancredi, Barrios, Ferreira ${ }^{(18)}$ : "É pouco provável que na prática alguém siga ipsis litteris um determinado método apenas” (p.7).

\section{Diagnóstico no planejamento das equipes de saúde}

No que se refere à formalização, o diagnóstico tendeu a ser burocrático para o grupo A, reflexo da racionalidade técnico-intrumental exacerbada, o que tende a agudizar conflitos, sufocar o diálogo e dificultar o processo de mudanças. Os demais grupos mostraram maior informalidade, o que denota planejamento mais comunicativo. Salienta-se que os suportes dos profissionais para a análise da situação de saúde restringiram-se a livros de registro auto-elaborados, formulários e indicadores, levando a crer que as tecnologias envolvidas no trabalho classificam-se como leve para o Grupo C (por prevalecer uma abordagem mais relacional) ou leve-duras, para os Grupos A e B (onde o uso de instrumentos é acentuado e intermediário, respectivamente). A tecnologia leve (compreende o vínculo, a autonomização, o acolhimento e a forma de gestão dos processos de trabalho); as tecnologias leve-duras (incluem saberes estruturados como a clínica médica, psicanálise e epidemiologia) e as tecnologias duras (abrangem equipamentos tecnológicos como máquinas, normas e estruturas organizacionais $)^{(19)}$. 
Quanto à complexidade, foi consenso que planejar é fácil, operacionalizar e avaliar são mais difíceis, conforme a evidência: "A gente tem dificuldade para executar e avaliar.. para executar por conta das condições, o Ministério diz: quero uma cobertura de 100\% das gestantes, mas até para fazer busca ativa... vou fazer que dia? Se, de segunda a sexta, tenho que atender, coordenar... e avaliar, então, mais difícil ainda... sempre deixamos algo sem fazer... então, se vou fazer um curso de gestante, como a gente fez...o Bem-Vindo a Vida... naqueles dias dos encontros, vou deixar de atender outros grupos... A gente trabalha com as prioridades e muitas vezes não damos conta... $O$ avaliar resultados é a mais dificil porque tem que rever planejamento, execução, resultados e todos os dados. Isso requer tempo, e a gente não tem... a avaliação... termina que a gente não faz..." (Grupo A).

No que diz respeito à importância do diagnóstico comunitário, percebeu-se que o mesmo é subutilizado. Mudar essa perspectiva exige ir além de diagnosticar para simplesmente obter dados sobre a realidade, é preciso usar as informações de modo que possam nortear a prática das equipes para que os instrumentos empregados sejam de fato estratégico-situacionais e não meramente normativos e sem efetividade. Percebeu-se que a construção do diagnóstico foi feita por ser determinação da Regional de Saúde do que propriamente uma necessidade sentida pelos profissionais. Não obstante, identificam o seu valor, embora não o qualifiquem como atividade de primeira instância, por falta de aplicabilidade: "a gente tem o diagnóstico, mas não tem o trabalho em cima. Começa a fazer, mas não tem como dar continuidade... a gente não tem perna para isso" (Grupo A).

Quanto aos objetivos, destaca-se uma gestão orientada para resultados, priorizando indicadores ministeriais e locais, onde os problemas baseiam-se em evidências, disponibilizados pelos sistemas de informação, apesar das fragilidades do Sistema de Informação da Atenção Básica (SIAB) ${ }^{(20,21)}$. Como consequência as equipes adotam a Avaliação para a Melhoria da Qualidade (AMQ) como forma de complementá-lo em suas limitações.

AAMQ é um projeto de intervenção inserido no contexto municipal da Atenção Básica. Oferece instrumentos para avaliação-planejamento-gestão, com os objetivos de monitorar os estágios de qualidade das ESF, disponibilizar ferramentas para o diagnóstico situacional, além de possibilitar a identificação de áreas críticas e apoiar os gestores no desenvolvimento de planos de ação tanto no que se refere à organização quanto às práticas. Apresenta como diretrizes: auto-avaliação; livre adesão; ausência de incentivos ou punições relacionadas a resultados; gestão interna da qualidade e metodologia dinâmica e sistêmica ${ }^{(22)}$.

Apresenta como pontos positivos a reflexão da prática; constitui momento de integração da equipe e sua metodologia impulsiona aperfeiçoamento, flexibilidade para mudanças, além de perseverança na ação ${ }^{(22)}$. Compartilha-se aqui com a idéia de que a AMQ é um instrumento sensível, uma vez que permite detectar fragilidades no sistema: “... ajuda a ver o que já fizemos e o que falta para melhorar" (Grupo B). 
Os aspectos negativos incluem os questionamentos dicotômicos; proposição de parâmetros universais para a saúde da família, desconsiderando que o trabalho em saúde é diverso em suas práticas, concepções, condições de estrutura e resultados, o que faz com que o padrão torne-se surreal e distante da realidade loco regional, corroborando com o pensamento do grupo A: “...é uma utopia"; sujeição a vieses, já que o avaliador é interno; o julgamento de alguns itens é subjetivo, por faltar registro de dados e informações. Outro ponto negativo é a extensão dos cadernos da AMQ, que demanda tempo para responder às perguntas e traçar a matriz de intervenção: "não é uma coisa fácil de trabalhar..." (Grupo B). A Autoavaliação para Melhoria do Acesso e da Qualidade (AMAQ) versão atualizada da AMQ, diferencia-se na simplificação, conteúdo das perguntas, que evolui da dicotomia para avaliação baseada em escores, reduzindo a subjetividade e está vinculada ao repasse de recursos financeiros aos municípios que aderirem a proposta ${ }^{(23)}$.

No que concerne às perspectivas, as equipes reconheceram a dificuldade em satisfazer de forma integral às necessidades de saúde da área, ficando as ações mínimas preconizadas à margem do processo. Como lacuna foi apontada a Saúde do Adolescente, a Saúde do Homem, a atenção aos acamados - cuidadores e a educação em saúde coletiva, eixos negligenciados.

Os anseios do Grupo A para melhorias no planejamento, perpassa por: a) Redivisão territorial para diminuir quantitativo de famílias; b) Menor exigência para a enfermeira e maior envolvimento dos demais profissionais de nível superior, já que teoricamente também são coordenadores da equipe. Essa articulação é essencial para que reine o processo interdisciplinar no qual progressivamente os núcleos de competência específicos vão enriquecendo o campo comum de competências, o que amplia a capacidade de cuidado do usuário ${ }^{(3)}$; c) Exigência à equipe de planejamentos setoriais (que priorize os grupos de atendimento) e unificados (enfatizando as programações comuns e específicas de cada profissional); d) Integralidade das ações, contemplando demanda espontânea, programática e busca ativa nas ações de vigilância epidemiológica; e) Realizar mutirões para melhorar as metas, embora reconheçam que essa estratégia possa eventualmente falhar em razão da demanda reprimida, carência de profissionais, além da falta de governabilidade de problemas que requerem suporte de outros atores: "Fizemos o mutirão da citologia... vieram quatro enfermeiras de outras unidades para ajudar, só que não conseguimos a meta. Tínhamos um número $x$, e, no decorrer, esse número aumentou para 3x. Isso foi a prova cabal de que uma equipe é insuficiente para atender às necessidades da área. A população de mulheres é muito grande! E isso foi um marco! Não conseguimos $50 \%$ com a ajuda de 4 colegas".

\section{Facilidades e Limites}

Apontam-se como facilitadores elementos inerentes ao profissional tais como a criatividade, o perfil e a motivação, sendo esta apontada como fator de maior impacto para enfrentar os fatores adversos que surgem no percurso.

Em relação à equipe, foram mencionados os aspectos organizativos, a boa integração interpessoal 
e a execução de funções peculiares ao cargo ocupado, pois no dizer de um participante: “... para que as coisas deem certo, cada qual no seu quadrado". Destaca-se que os profissionais tendem a idealizar o trabalho em equipe como aquele com dinâmica constantemente harmônica, homogênea, consensual, caracterizada por acordos recíprocos e com partilha das ações, sendo o cerne do conceito 'trabalho em equipe', a ausência de conflitos.

É preciso desmistificar esses axiomas. Quando a equipe multidisciplinar pensa igual diante de contextos com problemas mal-estruturados é certo que os profissionais nas suas arenas de decisão não serão atores sociais, por conta do processo de alienação: reinará apenas o seu saber técnicoadministrativo, ficando à deriva o saber político. Em toda mesa de negociação espera-se opiniões diferentes para os problemas por conta da disputa de poder e hegemonia de classe(s). Conjuntura como essa mantém o crescimento da equipe e viva a vontade de perseverar no plano, pois no dizer de Testa $^{(24)}$, todo processo de trabalho enquanto relação social ou de poder é responsável pela construção e transformação dos sujeitos individuais em sujeitos sociais, os quais se transformam em sujeitos coletivos (grupos/classes) como decorrência de práticas concretas. E, finalmente, os sujeitos coletivos se configuram atores sociais em contextos de ações estratégicas, quando problematizam as relações sociais, reivindicam espaços de poder e lutam por transformação para não cair na rotina e no comodismo (grifos nossos), a exemplo da experiência exitosa:

"A gente tem que trabalhar com a motivação dos ACS..., a instituição não trabalha. Começou uma onda de desmotivação na equipe, e dois ACS me procuraram..., tinh a caído na rotina, estavam sem vontade para trabalhar: ganha pouco, tem que ser exclusivo, coisa demais para preencher, e aí eu tive uma idéia: fazer uma premiação simbólica para aquele agente que tivesse melhor desempenho... Então... eu comprei um presente simbólico,... procurei avaliar só as ações que o agente faz... aquele que ganhou o $1^{\circ}$ lugar colocamos a foto no mural com uma mensagem parabenizando... eles gostaram! Essa avaliação foi feita ao longo de um ano. Com seis meses, a Regional conheceu o trabalho e pediu para a gente apresentar na Mostra... tivemos várias melhorias: indicadores, registros e motivação da equipe. ...Começamos a fazer bazar, rifas e outras atividades na comunidade e extra-horário para angariar recursos e dinheiro... para premiar o ACS... foi ótimo, o $1^{\circ}$ lugar foi premiado com um salário mínimo dado pela própria equipe” (Grupo A).

Com relação à população, os profissionais referem a credibilidade na eSF, destacando-se a cultura da comunidade da zona rural, que não se volta tanto para o consumismo exacerbado de exames, procedimentos e medicamentos, valorizando o ritual da consulta com orientações educativas, postura essa inexistente nas sociedades urbanas em razão do imaginário arraigado do grande complexo industrial da saúde, que friza que o bom atendimento transcorre um quantitativo quase interminável de encaminhamentos, herança procedente do hospitalocentrismo. Além dessas questões, pontuaram-se a intersetorialidade da ESF com programas governamentais, a exemplo do Programa Bolsa Família, que implicou melhorias nos indicadores sociais e da saúde, qualificandose como redutor da pobreza e desnutrição, o que faz lembrar o pacote assistencial básico em saúde proclamados em Alma Ata (1978), como forma de aplacar o estado de subdesenvolvimento e 
iniquidades.

Em síntese os facilitadores para a institucionalização do planejamento são: conhecimento de lideranças e movimentos sociais; participação de instituições de ensino; presença de monitores, que atuam como mediadores de conflitos para as ESF; monitoramento sistemático e intercedido por técnicos experientes; apropriação de um modelo lógico; envolvimento administrativo da gestão do SUS; qualificação e efetivação dos profissionais; diálogo intersetorial; consideração como critérios os problemas baseados em evidências e existência de programas consolidados ${ }^{(25)}$.

Limita a prática do planejamento o perfil territorial com as suas nuances, tais como área extensa, vulnerável, com precária infraestrutura, excesso de famílias acompanhadas além de diferentes perfis de usuários: 1) que incompreendem a missão dos serviços; 2) que preferem o atendimento tradicional a palestras educativas; 3) que resistem a mudanças; 4) que apresentam incompatibilidade entre o horário de trabalho e o funcionamento da unidade; 5) que não comparecem às consultas por dependerem de vale social, além daqueles que migram periodicamente de um bairro para outro.

Na unidade de saúde percebeu-se que os nós foram:

1) Estrutura física inadequada ao funcionamento da eSF, sendo retrocesso, a sua (re) inserção em ambiente hospitalar ao invés dos centros de saúde, que são os estabelecimentos assistenciais preconizados pelo Ministério da Saúde; 2) Questões organizativas dos serviços com os quais a eSF dialoga, dentre os quais destacam-se: o Serviço de Arquivo Médico - SAME, a farmácia e a direção da unidade. Como entraves no SAME foram mencionados: insuficiência de pessoal, despreparo dos funcionários quanto aos pressupostos da eSF, descumprimento de ordens da direção, não seguimento do cronograma de atendimento dos profissionais, bloqueio do acesso da população, autoritarismo, além de problemas organizacionais, a exemplo da avaria dos prontuários e da não permanência de funcionários no setor para orientar o sistema de consultas.

Com relação à farmácia, mencionaram a falta de apoio do setor na organização de alguns programas (Hiperdia), além da carência de medicamentos básicos para satisfazer as demandas: “... fizemos um mutirão fora do hospital, no colégio aqui ao lado... paramos por semanas. Fizemos tudo... pesamos, fizemos a glicemia, a classificação de risco, cadastros... tem pacientes que ia a farmácia com um mês, outros com dois meses e outros com três meses. A farmácia barrou... disse que não tinha condição... então, isso angustiou muito a gente... foi um trabalho feito em vão... continuamos sobrecarregados com os hipertensos/diabético e ... isso é apenas a pontinha do iceberg” (Grupo A). “... às vezes a gente fica com o paciente sem saber o que fazer... falta medicação para gestante com infecção urinária... isso eu acho um absurdo..." (Grupo C.)

No tocante à direção da unidade de saúde, citam como empecilhos o perfil do administrador e a cultura organizacional vigente, conforme os enunciados: "Nós já tivemos problemas com a direção anterior por não conhecer o sistema de trabalho do PSF. Então, ... tem que treinar e 
capacitar inclusive os gestores. Como vão administrar? Alguns não têm esse conhecimento”. “... o funcionário que sai não passa para o outro que tá chegando... a rotina, e talvez não tenha essa obrigação... é a instituição que tem que se preocupar com isso..." (Grupo A).

O perfil dos gerentes é determinante para o planejamento. O estilo administrativo continua determinado pela dinâmica de mercado onde não se prioriza tanto a experiência e a capacidade técnica, mas sim o grau de confiança, subordinação e apadrinhamentos políticos. O planejamento ou a improvisação decide-se na agenda do dirigente, e na forma como administra seu tempo e foco de atenção ${ }^{(25)}$. No setor saúde, o papel de gerentes eficientes caracteriza-se por apagar incêndios, fazer a máquina funcionar sem ter planos, simplesmente administra o status quo, exercendo controle da homeostase, porém sem apontar direcionamentos, o que ratifica a ideia de ser plenamente possível gerenciar sem planejar ${ }^{(18)}$.

Quanto ao processo e condições de trabalho das equipes destacaram-se: tempo escasso para planejar estratégias; a falta de triagem dos problemas nas visitas domiciliares; ausência de iniciativa para as atividades de educação em saúde; burocracia, evidente no quantitativo de relatórios e registros, o que acarreta sobrecarga de trabalho, especificamente para enfermeiras; falta organização dos dados nos sistemas de informação, principalmente SIAB e SISHIPERDIA; fragmentação do trabalho, no que diz respeito à difícil articulação entre a saúde da família e a saúde bucal, sendo isso atribuído à falta de materiais e à especificidade da consulta odontológica, caracterizada por menor número de atendimentos e cronogramas diferenciados.

Quanto à gestão do trabalho, frisaram como dificultadores: profissionais não-concursados assumindo os cargos, o que faz propagar a falta de vínculo, compromisso e envolvimento, perpetuando a ideia de estar na eSF de passagem; a ausência do profissional médico; denúncias em relação aos ACS; as capacitações isoladas instiga a fragmentação e hierarquização do processo de trabalho; o negligenciamento quanto ao treinamento introdutório, quer na implantação das equipes ou a posteriori; inexistência de uma rede organizada de atenção à saúde; modo de conduzir as supervisões de equipe, que fiscaliza o enfermeiro em detrimento das demais categorias, além da invisibilidade dos conselhos locais de saúde.

Um estudo realizado em 12 municípios apresentou resultados similares apontando como obstáculos para o planejamento: ausência de dados, inconsistência dos mesmos, centralização das informações, sistemas de informação frágeis; instabilidade política com mudança de gestores; dificuldades da gestão em aceitar divulgar as evidências; institucionalização de ações que não se encaixam em programas já existentes e atribuir o monitoramento das ações como tarefa exclusiva da gestão(26).

\section{CONSIDERAÇÕES FINAIS}

O diagnóstico comunitário norteia as ações da eSF? O planejamento no contexto da Atenção 
Básica em Saúde é incipiente e não participativo independente do cenário analisado (hospital ou centro de saúde), da área (urbana ou rural), do tempo de implantação das equipes (recente ou antiga) e do modelo adotado (PSF ou PACS). O planejamento exige como pré-requisito o diagnóstico comunitário de saúde, que é subutilizado no cotidiano de trabalho, apesar de os profissionais reconhecerem a sua importância. Observou-se que o nó - crítico que dificultou o processo de planejamento participativo foi o não oferecimento do treinamento introdutório na implantação das equipes. Isso pode ter potencializado a omissão da comunidade e a inexpressividade dos conselhos locais de saúde no exercício do controle social.

A territorialidade da área adstrita é explorada sob a forma de mapeamentos que disponibilizam as microáreas de risco, os problemas de saúde, recursos comunitários e quantitativo de famílias acompanhadas. A formalização do diagnóstico tendeu a ser mais burocrático no grupo hospitalar, já nos centros de saúde, maior informalidade.

O plano assistencial da equipe multiprofissional assume uma conotação mais individualizada do que coletiva. Cada profissional elabora os cronogramas de atendimento focalizando a demanda programática. A participação dos técnicos nas reuniões não costuma ocorrer de forma homogênea para todas as categorias, e isso revela características do processo de trabalho específico de cada profissão e estilo de gestão.

As reuniões abordam assuntos administrativo-normativos, sendo pouco valorizado a discussão de estratégias para implementar ações. Como exceção tem-se a AMQ momento único de avaliação dos possíveis avanços ou retrocessos no processo de trabalho. Como contraponto tem-se um planejamento voltado para curto prazo e que satisfaz as necessidades da demanda programática e espontânea. Permanece ainda a lacuna em relação à saúde do homem, saúde do adolescente, atenção aos acamados, educação em saúde coletiva com grupos e realização de busca ativa nas atividades de vigilância epidemiológica. Outro entrave à integralidade da atenção está no referenciamento dos clientes às especialidades, pois o fluxo dos encaminhamentos não está documentado em protocolos, o que faz com que os profissionais fiquem alheios, além de outras dificuldades, como tempo de espera para marcação de consultas e ausência de contrarreferência.

As equipes investigadas valorizam os indicadores ministeriais e locais, pactuados pelo município de Teresina, o que contribui para que os problemas sejam baseados em evidências e fundamentados nas informações disponibilizadas pelos Sistemas de Informação em Saúde, apesar das fragilidades.

A prática do planejamento é influenciada por questões tais como, a quantidade de vínculos trabalhistas dos profissionais, perfil profissional, condições de trabalho, remuneração, capacitações e treinamentos destinados às equipes e o modo de realização das supervisões. São alvos de reflexão os investimentos em tecnologias que facilitem e simplifiquem o processo de trabalho, bem como o processo comunicativo intraequipe e com os demais setores com que a eSF dialoga.

A administração da situação-problema pelas equipes ocorre à medida que os fenômenos vão ISSN 1982-8829 
acontecendo, sem visão de longo-prazo, o que torna o planejamento fragmentado, incompleto, desarticulado e incipiente, permanecendo a visão do diagnóstico comunitário como mera formalidade.-

Sugere-se a necessidade de fortalecer os conselhos locais de saúde. É a partir dessa organização que a equipe pactua a programação da unidade, elabora o diagnóstico do território e a agenda de seguimento e avaliação das atividades além do monitoramento dos indicadores. Urge desmistificar a ideia de atribuir à atenção básica conotação de serviço primário. Como é a porta de entrada do SUS, é imperioso investir em tecnologia para que se tenha qualidade nas decisões tomadas pelos gestores, profissionais, além de oferecer transparência aos usuários.

Para facilitar o processo de trabalho é indispensável informatizar o SIAB, capacitar os profissionais a trabalhar seletivamente os indicadores mais oportunos da área. Para os ACS seria interessante a implantação de palmtops o que forneceria subsídios à equipe em tempo real para planejar ações, já que a coleta e atualização dos dados ocorreriam nas visitas domiciliares. Além disso, é imprescindível implantar nas unidades prontuários eletrônicos, instituir unidades móveis de saúde para prestar serviços, em áreas vulneráveis e zonas rurais.

\section{REFERÊNCIAS BIBLIOGRÁFICAS}

1.Mendes EV. A atenção primária no SUS. Fortaleza: Escola de Saúde Pública do Ceará, 2002.

2.Silva NC; Garnello L; Giovanella L. Extensão da cobertura ou reorganização da atenção básica? A trajetória do PSF de Manaus - AM. Saúde Soc 2010; 19(3): 592-604.

3. Ministério da Saúde (BR). Portaria No 2.488, de 21 de outubro de 2011. Diário Oficial da União; Poder Executivo. Brasília (DF), 24 de out. 2011. Seção 1, p. 48-55.

4. Felisberto E. Da Teoria à formulação de uma Política Nacional de Avaliação em Saúde: reabrindo o debate. Ciência \& Saúde Coletiva 2006; 11(3): 553-563.

5. OPAS. Participação da comunidade e articulação interinstitucional: dois fios condutores para a sustentabilidade da comunicação de risco. 2003. Disponível em: http: www.opas.org.br/ ambiente/risco/tutorial6/p/pdf/tema 07.pdf. Acessado em 31/01/2011.

6. OMS. Relatório mundial de saúde. Atenção Primária em saúde - Agora Mais do que Nunca, 2008 .

7. Ministério da Saúde (BR). Conselho Nacional de Secretários de Saúde. Atenção Primária e Promoção da Saúde. Brasília (DF): CONASS; 2007, v.8, cap.3, pp.54-68.

8. Teresina. Fundação Municipal de Saúde. Conselho Municipal de Saúde. Regimento Interno dos Conselhos Locais. Teresina,1993. 
9. Pedrosa JIS; Telles JBM. Consenso e diferenças em equipes do Programa Saúde da Família. Rev.Saúde Pública 2001; 35(3): 303-11.

10. Moken M; Barcellos C. Vigilância em Saúde e território utilizado: possibilidades teóricas e metodológicas. Cad. Saúde Pública 2005; 21(3): 898-906.

11.Bardin L. Análise de conteúdo. Lisboa: Edições 70; 1995.

12. Ministério da Saúde (BR). Secretaria de Atenção à Saúde. Departamento de Atenção Básica. Política Nacional da Atenção Básica. Brasília (DF): Ministério da Saúde; 2006.

13. Nascimento MS; Nascimento MAA. Prática da enfermeira no Programa de Saúde da Família: a interface da vigilância da saúde versus as ações programáticas em saúde. Ciência \& Saúde Coletiva 2005; 10(2): 333-345.

14. Sousa MF. O programa saúde da família no Brasil: análise do acesso à atenção básica. Rev Bras Enferm 2008; 61(2): 153-158.

15. Kell MCG; Shimizu HE. Existe trabalho em equipe no PSF? Ciência \& Saúde Coletiva 2010;15 (Supl.1): 1533-1541.

16. Santana ML. Demanda espontânea e planejamento estratégico situacional no Programa Saúde da Família de Pindamonhangaba. 2008. 208fl. Dissertação (Mestrado em Gestão e Desenvolvimento Regional). Universidade de Taubaté, São Paulo, 2008.

17. Campos RO. O planejamento no labirinto: uma viagem hermenêtica. São Paulo: Hucitec; 2003.

18. Tancredi FB; Barrios SRL; Ferreira JHG. Planejamento em saúde. São Paulo: Faculdade de Saúde Pública da USP; 1998. v.2.

19. Merhy EE. Em busca do tempo perdido: a micropolítica do trabalho vivo em saúde. In: Merhy EE; Onocko R. (orgs). Agir em saúde: um desafio para o público. São Paulo: Hucitec; 1997.

20. Silva AS, Laprega MR. Avaliação crítica do SIAB e de sua implantação na região de Ribeirão Preto, São Paulo, Brasil. Cad. Saúde Pública 2005; 21(6): 1821-1828.

21. Freitas FP, Pinto IC. Percepção da equipe de saúde da família sobre a utilização do Sistema de Informação da Atenção Básica - SIAB. Rev. Latino-Am.Enfermagem 2005; 13(4): 547-554.

22. Ministério da Saúde (BR). Secretaria de Atenção à Saúde. Departamento de Atenção Básica. Avaliação para melhoria da qualidade da estratégia saúde da família (AMQ). Brasília (DF): Ministério da Saúde; 2005. 
23. Ministério da Saúde (BR). Secretaria de Atenção à Saúde. Departamento de Atenção Básica. Autoavaliação para a Melhoria do Acesso e da Qualidade da Atenção Básica: AMAQ, Brasília (DF): Ministério da Saúde; 2012.

24. Testa M. Pensamiento Estatégico y Lógica de la Programación. Estratégia y Programación. Buenos Aires, Argentina, 1986.

25. Cubas MR. Planejamento local: a fala do gerente da Unidade Básica de Saúde. Rev. bras enferm 2005; 58(3): 278-283.

26. Sousa MF e colaboradores. Relatório de Avaliação do Projeto AGAP - Aperfeiçoamento da Gestão da Atenção Primária: fortalecendo a atenção primária à saúde no Brasil e no Canadá, um projeto de intercâmbio de conhecimentos para a equidade. Brasília: Universidade de Brasília; Nesp, 2010.

Artigo apresentado em 15-05-14

Artigo aprovado em 12-07-14 Artigo publicado no sistema em 28-12-14 